\section{The use of facilities for labor and delivery: the views of women in rural Uganda}

\author{
Rebecca Newell, ${ }^{1}$ Ian Spillman, ${ }^{2}$ \\ Marie-Louise Newell ${ }^{1}$ \\ ${ }^{1}$ University of Southampton, UK; \\ ${ }^{2}$ Kisiizi Hospital, Uganda
}

\begin{abstract}
The aim of the paper is to explore factors associated with home or hospital delivery in rural Uganda. Qualitative interviews with recently-delivered women in rural Uganda and statistical analysis of data from the 2011 Ugandan Demographic and Health Survey (DHS) to assess the association between socio-demographic and cultural factors and delivery location in multivariable regression models. In the DHS, $61.7 \%$ (of 4907) women had a facility-based delivery (FBD); in adjusted analyses, FBD was associated with an urban setting [adjusted odds ratio (aOR) 3.38, 95\% confidence interval (CI) 2.66 to 4.28)], the upper wealth quintile (aOR: $3.69,95 \%$ CI 2.79 to 3.87 ) and with secondary education (aOR: 3.07 , $95 \%$ CI 2.37 to 3.96 ). In interviews women quoted costs and distance as barriers to FBD. Other factors reported in interviews to be associated with FBD included family influence, perceived necessity of care (weak women needed FBD), and the reputation of the facility (women bypassed local facilities to deliver at better hospitals). Choosing a FBD is a complex decision and education around the benefits of FBD should be combined with interventions designed to remove barriers to FBD.
\end{abstract}

\section{Introduction}

In 2015 approximately 125 million women gave birth, of which 303,000 died, leaving countless children motherless, increasing infant deaths via perinatal conditions and sub-optimal care and restricting economic progress.1 Nearly all deaths $(99 \%)$ were in resource-poor countries, with $66 \%$ in [sub-Saharan Africa (SSA)]. ${ }^{1}$ Maternal mortality (MM) and morbidity are largely blamed on poor access to obstetric care, especially intrapartum, with the period around labour and delivery bearing the highest risk. ${ }^{2,3}$ Consequently, a facilitybased delivery (FBD) is an effective way to reduce MM. ${ }^{4-6}$ Millennium Development
Goal 5 (MDG-5) was created in response to the thousands of maternal deaths from preventable and treatable causes, with the aim to reduce MM by $75 \%$ by 2015 through providing universal access to reproductive healthcare. ${ }^{5-7}$ Progress has been made in reducing MM globally, with an estimated $45 \%$ reduction since 1990 , and deliveries attended by a skilled birth attendant (SBA) increasing to $71 \%$ in 2014 compared to $55 \%$ in $1990 .{ }^{1}$ However, the Maternal Mortality Ratio (MMR) has not fallen by the $75 \%$ original target. ${ }^{1}$ Despite effective strategies and interventions, reducing maternal deaths in resource-poor countries remains a challenge. ${ }^{2}$

Uganda has a high MMR; 360 in 2014, and despite improvements in FBD rates and increasing numbers of health centres providing community-based care, for some women facilities are still inaccessible and underused. $1,5,8$ The reasons for low-uptake of FBD are wide-ranging, complex and context specific, transforming the causes of MM from a number of treatable and preventable medical conditions to a wide range of complex, interlinking socio-cultural factors. $^{9-12}$ To receive FBD women must logistically be able to access a facility and they, or a family-member must make the decision to seek it. ${ }^{12-14}$ Therefore, it is important to understand the factors that encourage FBD and those act as barriers, to fully reap the benefits of the increasing availability of reproductive healthcare brought about by MDG-5. ${ }^{11,15,16}$ Recognising a gap in research on socio-cultural factors and their influence on delivery location, this study, through interviews with women and analysis of the Ugandan 2011 DHS aims to inform understanding of decision-making and issues associated with choice of place of delivery.

\section{Materials and Methods}

Thirty women from Kisiizi, Uganda, were interviewed in early 2015 . This location was utilised to facilitate the interviews due to its rural setting. Purposive sampling was used to ensure a range of delivery locations, and women were recruited through Kisiizi hospital post-natal services, paediatric services or through outreach clinics. All women approached were willing to participate and provided with participant information sheets. Written consent was obtained from each participant. Ethical approval was granted by both the University of Southampton and the ethics board of Kisiizi Hospital. The inclusion criteria were aged between 15 and 49 years,
Correspondence: Rebecca Newell, Frampton Cotterell, Bristol, BS362EJ, UK.

Tel.: +44.07923314874

E-mail: becky.t.newell@googlemail.com

Key words: facility-based delivery; Uganda; delivery location.

Acknowledgements: the authors would like to thank staff from Kisiizi hospital, and the women who gave up their time to participate. We would also like to thank members of staff from the University of Southampton faculty of Medicine, specifically the statistics team for their help and input. The Victoria foundation and wellbeing for women trust that financially enabled the research to take place and finally the DHS program for allowing us to use the available 2011 data for Uganda.

Contributions: RN and MLN designed the project, RN collected and analysed the data, $\mathrm{RN}$, IS and MLN interpreted the results. RN drafted the first version of the paper, MLN and IS contributed to subsequent versions. All authors agreed the final version for submission.

Conflict of interest: the authors declare no potential conflict of interest.

Funding: RN, as an undergraduate medical student received the wellbeing for women foundation elective bursary and The Victoria foundation undergraduate bursary to enable her to carry out the research.

Received for publication: 16 August 2016

Revision received: 13 June 2017.

Accepted for publication: 14 June 2017

This work is licensed under a Creative Commons Attribution NonCommercial 4.0 License (CC BY-NC 4.0).

(C) Copyright R. Newell et al., 2017

Licensee PAGEPress, Italy

Journal of Public Health in Africa 2017; 8:592

doi:10.4081/jphia.2017.592

having had a delivery of a live-born infant in the past five years and consent; women who were currently pregnant were excluded. Women were interviewed in a secure and private location by the researcher and a translator, following a semi-structured questionnaire. Data were recorded via notetaking on printed questionnaires. The interviews have been explored, analysed and described using thematic analysis. These interviews explored a number of topics concerning women's beliefs around place of delivery and how they make the decision about where to deliver, including: opinions about healthcare, socio-demographic factors, knowledge about the benefits of hospi- 
tal care, and socio-cultural beliefs about pregnancy and place of delivery.

These topics provided a basis upon which themes were identified and are used to present the results.

Published in 2011, the most recent DHS from Uganda provides information of delivery locations within the country. The DHS is a large, nationally representative, crosssectional survey. Women were asked to report on any births that occurred up to five years prior to interview. The DHS data was entered into the statistical package (SPSS, IBM v22) with an analysis dataset created by merging Child, Birth and Individual datasets. The inclusion criteria for the DHS section of the study were participants present at the time of interview, female, aged between 15-49, at least one delivery and an outcome for place of delivery. This gave a total of 4907 women. Children and births were only included in the dataset if they were matched with a woman's data. A proportion of women had multiple children, thus giving a total of 20,869 births. The latest birth for each woman was selected for statistical analysis to align in time as closely as possible with the qualitative interviews, giving a total of 4907 births. The data was analysed using descriptive statistics, uni- variate and multivariable logistic regression analysis. Variables were selected, categorised and then built into regression models to be statistically informative, least affected by missing data, represent the available literature and to align with the qualitative themes.

The variables were split into accessibility-related factors which included distance to health facility, accessing money for treatment, means of transport owned by household, attaining permission to go, person who usually dictates how respondents earnings are spent and the person most likely to make decision regarding respondents healthcare; maternal-related factors: current marital status, age in five year groupings, type of place of residence, education level, wealth index and total number of children. Facility-related factors included being informed about pregnancy complication, number of ANC visits, use of contraception, vaccination status and visiting a health facility in the last 12 months.

Place of delivery was either home delivery, facility-based or other. Home delivery includes all births at respondent's home, Traditional Birth Attendants (TBA) home or other private residence. Facility-based deliveries included births at a government or private hospitals or health centres, private clinics or other institutions. The outcome in the logistic regression model is facility-based delivery (Yes/No).

\section{Ethical approval}

The Kisiizi Hospital Ethics Board chaired by Dr Banya approved the study on 10/11/2014; the University of Southampton Ethics Board, ERGO 12383, approved the study on $16 / 11 / 2014$.

\section{Results}

Respondents to the qualitative interviews had between one and eight children and were from a variety of locations, including rural areas and towns. Some women were professionals, including a teacher and a health worker, while others were peasant farmers and homemakers.

In the 2011 Uganda DHS of the 4,907 eligible deliveries, $61.7 \%$ (3030) occurred at a facility, $37.3 \%(1829)$ at home and $1 \%$ (48) in another location.

\section{Factors related to accessibility}

In multivariable analysis (Table 1),

Table 1. Univariate and multivariable regression analysis of the association between facility-based delivery and accessibility factors, Uganda DHS 2011, 4907 women in total.*

\begin{tabular}{|c|c|c|c|c|c|c|c|}
\hline \multirow[t]{3}{*}{ Background/variable } & \multicolumn{3}{|c|}{ Univariate } & \multicolumn{4}{|c|}{ Multivariable } \\
\hline & \multirow{2}{*}{ OR } & \multicolumn{2}{|c|}{$95 \% \mathrm{CI}$} & \multirow[t]{2}{*}{$\mathrm{aOR}$} & \multicolumn{2}{|c|}{$95 \% \mathrm{CI}$} & \multirow[t]{2}{*}{ Sig } \\
\hline & & Lower & Upper & & Lower & Upper & \\
\hline \multicolumn{8}{|l|}{ Distance to health facility } \\
\hline Big problem (ref) $n=2129$ & 1.00 & & 1.00 & & & & \\
\hline Not a big problem $n=2774$ & 2.07 & 1.84 & 2.32 & 1.77 & 1.46 & 2.13 & $<0.001$ \\
\hline \multicolumn{8}{|l|}{ Getting money for treatment } \\
\hline Big problem (ref) $n=2582$ & 1.00 & & 1.00 & & & & \\
\hline Not a big problem $n=2321$ & 1.88 & 1.67 & 2.11 & 1.54 & 1.27 & 1.87 & $<0.001$ \\
\hline \multicolumn{8}{|l|}{ Means of transport owned by household } \\
\hline Car/truck: No (ref) $n=4623$ & 1.00 & & 1.00 & & & & \\
\hline ar/truck: Yes $n=172$ & 4.47 & 2.85 & 7.02 & 5.33 & 2.43 & 11.67 & $<0.001$ \\
\hline Motorcycle/scooter: No (ref) $n=4623$ & 1.00 & & 1.00 & & & & \\
\hline Motorcycle/scooter: Yes n=403 & 1.85 & 1.47 & 2.33 & 1.28 & 0.92 & 1.76 & 0.14 \\
\hline \multicolumn{8}{|l|}{ Getting permission to go to healthcare facility } \\
\hline Big problem (ref) $n=273$ & 1.00 & & 1.00 & & & & \\
\hline Not a big problem $n=4630$ & 1.43 & 1.12 & 1.83 & 1.01 & 0.69 & 1.49 & 0.96 \\
\hline \multicolumn{8}{|c|}{ Person who usually decides how to spend respondents earning } \\
\hline Respondent alone (ref) $n=1229$ & 1.00 & & 1.00 & & & & \\
\hline Respondent + partner $\mathrm{n}=693$ & 0.81 & 0.67 & 0.98 & 0.86 & 0.69 & 1.07 & 0.17 \\
\hline Partner/husband alone $n=310$ & 0.56 & 0.44 & 0.72 & 0.59 & 0.45 & 0.77 & $<0.001$ \\
\hline Someone else $n=7$ & 3.12 & 0.37 & 25.96 & 2.91 & 0.34 & 25.34 & 0.33 \\
\hline \multicolumn{8}{|c|}{ Person who usually decides on respondents healthcare } \\
\hline Respondent alone (ref) $n=1024$ & 1.00 & & 1.00 & & & & \\
\hline Respondent + partner/husband: $n=1596$ & 1.04 & 0.88 & 1.22 & 1.00 & 0.79 & 1.26 & 1.00 \\
\hline Partner/husband alone $n=1484$ & 1.12 & 0.95 & 1.32 & 1.10 & 0.87 & 1.40 & 0.42 \\
\hline Someone else $n=11$ & 0.83 & 0.25 & 2.74 & 0.54 & 0.05 & 6.19 & 0.62 \\
\hline Other $n=7$ & 1.73 & 0.33 & 8.97 & 1.79 & 0.17 & 18.71 & 0.62 \\
\hline
\end{tabular}

*Factors that determine how accessible facilities are to women: distance to health facility, getting money for treatment, means of transport owned by household, getting permission to go, person who usually decides how to spend respondents earnings, and the person who usually decided on the respondents healthcare. OR, odds ratio; Lower, lower confidence interval; Upper, upper confidence interval; aOR, adjusted odds ratio; Sig, significance/P-value. 
allowing for accessibility factors, distance to the health facility, accessing money for treatment, getting permission to go and car ownership were independently associated with the likelihood of FBD; with finding overcoming these factors easier associated with FBD. Similarly, the interview respondents also almost universally quoted cost and distance as barriers to receiving a FBD. However, their specific effect on delivery location, according to these women, was also impacted by other factors, such as their economic situation, family and social context and their perceived care needs ( $\mathrm{PCN})$.

The effect of women's economic situation was seen in adjusted analysis of maternal variables in the DHS data (Table 2). Variables found to have independent significant positive association with FBD were living in an urban setting, increasing education levels and increasing wealth index. Higher maternal age and high number of children were seen to decrease the chance of FBD (Table 2). The qualitative inter- views again agreed with these results, finding that wealth, education and urban environment were reported to facilitate FBD through their influence on the barriers costs and distance.

Some women in interviews reported that the barriers of costs and distance removed all choice they had regarding place of delivery.

It was so fast that because of the distance and the transport I delivered at home. We had not money so we had to look for that too before I could go and we couldn't find a vehicle to take me.

Because of our place being far away from the hospital we deliver before coming because of the distance. There is no money, if there was money I could come and wait in the hospital. Even when the labour has started we cannot get the money to transport us to the hospital. My family and husband are happy for me to go to the hospital and the nurses say that it is best, but there is no money so how can I get to the hospital.

Other women explained how their jobs, family or social context enabled them to overcome barriers, and often allowed a choice between facilities, with examples of bypassing facilities to travel further or pay more to deliver at perceived better facilities.

My husband wanted me to go to the hospital though because it is better and we can afford it and have the transport, so that is not a problem.

Two hours by private taxi - we hire a car from someone where we live....It is not the local hospital - there are other hospitals where we come from but one of the doctors from the health centre recommended this hospital as it is one of the best.

Yes you don't know how much it will cost, but I don't really worry much about it because of the jobs of me and my husband and then the money we receive.

Table 2. Univariate and multivariable regression analysis of the association between facility-based delivery and maternal factors, Uganda DHS 2011, 4907 women in total.*

\begin{tabular}{|c|c|c|c|c|c|c|c|}
\hline \multirow{3}{*}{ Background/variable } & \multicolumn{3}{|c|}{ Univariate } & \multicolumn{4}{|c|}{ Multivariable } \\
\hline & \multirow[t]{2}{*}{ OR } & \multicolumn{2}{|c|}{$95 \% \mathrm{CI}$} & \multirow{2}{*}{$\mathrm{aOR}$} & \multicolumn{2}{|c|}{$95 \% \mathrm{CI}$} & \multirow[t]{2}{*}{ Sig } \\
\hline & & Lower & Upper & & Lower & Upper & \\
\hline \multicolumn{8}{|l|}{ Current marital status } \\
\hline Never in Union (ref) $n=216$ & 1.00 & & 1.00 & & & & \\
\hline Married $n=2338$ & 0.43 & 0.31 & 0.60 & 1.11 & 0.76 & 1.62 & 0.58 \\
\hline Living with partner $n=1790$ & 0.50 & 0.36 & 0.70 & 1.06 & 0.73 & 1.54 & 0.77 \\
\hline Widowed $n=118$ & 0.37 & 0.23 & 0.59 & 1.12 & 0.66 & 1.93 & 0.67 \\
\hline Divorced $n=34$ & 0.63 & 0.29 & 1.38 & 1.07 & 0.44 & 2.59 & 0.89 \\
\hline Not together/separated $n=409$ & 0.65 & 0.44 & 0.94 & 1.23 & 0.84 & 1.88 & 0.34 \\
\hline Age in 5 year groups & & & & & & & \\
\hline $15-19$ (ref) $n=375$ & 1.00 & & 1.00 & & & & \\
\hline $20-24 n=1181$ & 0.79 & 0.62 & 1.02 & 0.75 & 0.57 & 0.98 & 0.36 \\
\hline $25-29 n=1362$ & 0.65 & 0.50 & 0.83 & 0.70 & 0.52 & 0.94 & 0.02 \\
\hline $30-34 n=871$ & 0.59 & 0.46 & 0.77 & 0.74 & 0.53 & 1.04 & 0.85 \\
\hline $35-39 n=686$ & 0.63 & 0.47 & 0.82 & 1.00 & 0.69 & 1.45 & 0.99 \\
\hline $40-44 n=324$ & 0.46 & 0.34 & 0.63 & 0.77 & 0.51 & 1.18 & 0.23 \\
\hline $45-49 n=108$ & 0.37 & 0.24 & 0.57 & 0.80 & 0.46 & 1.39 & 0.43 \\
\hline \multicolumn{8}{|c|}{ Type of place of residence } \\
\hline Rural $n=3722$ & 1.00 & & 1.00 & & & & \\
\hline Urban $n=1185$ & 8.36 & 6.83 & 10.25 & 3.38 & 2.66 & 4.28 & $<0.001$ \\
\hline \multicolumn{8}{|l|}{ Education level } \\
\hline No education (ref) $n=858$ & 1.00 & & 1.00 & & & & \\
\hline Primary $n=2849$ & 2.40 & 2.06 & 2.81 & 1.71 & 1.44 & 2.03 & $<0.001$ \\
\hline Secondary $\mathrm{n}=967$ & 8.38 & 6.73 & 10.42 & 3.07 & 2.37 & 3.96 & $<0.001$ \\
\hline Higher $n=233$ & 37.31 & 19.51 & 71.35 & 9.01 & 4.55 & 17.84 & $<0.001$ \\
\hline \multicolumn{8}{|l|}{ Wealth index } \\
\hline Lowest (ref) $n=1193$ & 1.00 & & 1.00 & & & & \\
\hline Fourth $n=932$ & 1.86 & 1.56 & 2.21 & 1.53 & 1.27 & 1.83 & $<0.001$ \\
\hline Middle $n=840$ & 2.04 & 1.70 & 2.44 & 1.52 & 1.26 & 1.84 & $<0.001$ \\
\hline Second $n=794$ & 2.84 & 2.36 & 3.44 & 1.78 & 1.46 & 2.19 & $<0.001$ \\
\hline Highest $\mathrm{n}=1148$ & 14.07 & 11.21 & 17.67 & 3.69 & 2.79 & 4.87 & $<0.001$ \\
\hline \multicolumn{8}{|l|}{ Total number of children } \\
\hline $1-3$ (ref) $n=2303$ & 1.00 & & 1.00 & & & & \\
\hline $4-6 n=1562$ & 0.56 & 0.49 & 0.64 & 0.78 & 0.64 & 0.95 & 0.01 \\
\hline $7-10 n=923$ & 0.44 & 0.38 & 0.52 & 0.75 & 0.57 & 0.98 & 0.04 \\
\hline $11-15 n=119$ & 0.39 & 0.27 & 0.57 & 0.75 & 0.46 & 1.22 & 0.25 \\
\hline
\end{tabular}

*Maternal-related factors: current marital status, age in five year groups, type of place of residence, education level, wealth index and total number of children. OR, odds ratio; Lower, lower confidence interval; Upper, upper confidence interval; aOR, adjusted odds ratio; Sig, significance/P-value. 
A woman's family was another influential factor on whether she received a FBD. Who made financial decisions or decisions about healthcare providers, partner/husband alone or respondent alone etc. was not statistically associated with a specific delivery location in either univariate or multivariable analysis (Table 1). In univariate analysis women were more likely to receive FBD if they didn't find getting permission to go to a facility a big problem. However, after adjustment for other accessibility factors, this association was no longer statistically significant (Table 1). Through the interviews, family was seen to both enable and prevent FBD. Some families enabled FBD by giving permission, or allowing costs and distance to be overcome. Interviews also demonstrated how men or older family members often controlled the family's money and made major decisions.

Travel and the costs make a difference but it is not too far for me, and because my husband said I could go we had put the money ready so I was able to go. My husband and me made the decision together, he said I could go.

My husband wanted me to deliver in the hospital because it is better. For him the money doesn't matter, it is more about whether the wife delivers well and gets a healthy baby. Also because of the bleeding now we know it is very important that I go to the hospital, they can stop the bleeding there.

The father of my baby says that the hospital is too far and that having a baby is normal so I should stay at home.

From home, my husband was not at home when I started labouring and there was no one to attend to me or take me to the hospital. My husband does not like to spend the money when there is another way...My husband gave me no money to go and wasn't there to take me, so he meant I could not go.

I wanted to go to the hospital but later when I went into labour I delivered at home, I have no partner so I have to please my grandmother and not ask for a lot of things. My grandmother told me I was delivering at home and would have been very angry if I went to the hospital and they had to pay.

I am also very blessed that this is not a problem for me, but it is for many women here. They cannot pay the bills and their husbands won't give them the money. They have no money and are left in the house; there is nothing they can do. I try and tell the women to hide money for themselves when they get pregnant so they can come to the hospital.

\section{Maternal factors}

In addition to the factors discussed above, maternal factors include women's opinions and education around delivery location and their specific health and PCN. In the DHS, women who reported having been told about benefits of FBD were around 1.5 times more likely to have received FBD (Table 3). The majority of women interviewed stated that the hospital was the best place to deliver due to the availability of care, specifically emergency care.

I know the hospital is better for me, and the baby, and I think that it is worth the costs. It is worth the costs for you and your baby being okay.... can give the only disadvantage is the costs but I would rather pay a large cost than lose a child or life.

.... there is a time when you have a complicated labour or aggressive labour like the baby is in the wrong position and then you try to push at home but you can't and then they bring you to hospital and it is too late and you try and save the mother and baby but it is too late and you can't...

Safe, clean, free from infection, in case of complications and generally reduces the number of mother and baby deaths. Lots of things, like I said, they help you and can help if there are complications. It is much

Table 3. Univariate and multivariable regression analysis of the association between facility-based delivery and facility factors, Uganda DHS 2011, 4907 women in total.*

\begin{tabular}{|c|c|c|c|c|c|c|c|}
\hline \multirow[t]{3}{*}{ Background/variable } & \multicolumn{3}{|c|}{ Univariate } & \multicolumn{4}{|c|}{ Multivariable } \\
\hline & \multirow[t]{2}{*}{ OR } & \multicolumn{2}{|c|}{$95 \% \mathrm{CI}$} & \multirow[t]{2}{*}{$\mathrm{aOR}$} & \multicolumn{2}{|c|}{$95 \% \mathrm{CI}$} & \multirow[t]{2}{*}{ Sig } \\
\hline & & Lower & Upper & & Lower & Upper & \\
\hline \multicolumn{8}{|l|}{ Told about pregnancy complications } \\
\hline No (ref) $n=2148$ & 1.00 & & & 1.00 & & & \\
\hline Yes $n=2541$ & 1.47 & 1.31 & 1.66 & 1.49 & 1.23 & 1.79 & $<0.001$ \\
\hline Not sure $n=35$ & 0.87 & 0.44 & 1.69 & 2.24 & 0.70 & 7.19 & 0.18 \\
\hline \multicolumn{8}{|l|}{ Number of ANC visits } \\
\hline None (ref) $n=80$ & 1.00 & & 1.00 & & & & \\
\hline $1-5 n=1977$ & 2.84 & 2.08 & 3.89 & 1.69 & 1.25 & 2.29 & $<0.001$ \\
\hline $6-10 n=291$ & 4.68 & 3.26 & 6.74 & 1.05 & 0.18 & 6.15 & 0.95 \\
\hline $11-20 n=7$ & 4.52 & 1.36 & 15.01 & 3.36 & 1.54 & $\begin{array}{l}0.10 \\
7.35\end{array}$ & $<0.001$ \\
\hline \multicolumn{8}{|l|}{ Ever used contraception } \\
\hline Never (ref) $n=3519$ & 1.00 & & & 1.00 & & & \\
\hline Used only folklore method $n=18$ & 0.94 & 0.37 & 2.39 & 0.74 & 0.15 & 3.71 & 0.71 \\
\hline Used only traditional method $n=145$ & 2.12 & 1.44 & 3.10 & 2.04 & 1.11 & 3.75 & 0.02 \\
\hline Used modern method: $n=1225$ & 2.15 & 1.86 & 2.49 & 2.36 & 1.87 & 2.99 & $<0.001$ \\
\hline \multicolumn{8}{|l|}{ Visited a health facility in last 12 months } \\
\hline No (ref) $n=1120$ & 1.00 & & & 1.00 & & & \\
\hline Yes $n=3784$ & 1.16 & 1.01 & 1.33 & 0.99 & 0.79 & 1.22 & 0.89 \\
\hline \multicolumn{8}{|l|}{ Ever had a vaccination } \\
\hline No (ref) $n=275$ & 1.00 & & & 1.00 & & & $<0.001$ \\
\hline Yes $n=1781$ & 2.65 & 2.05 & 3.45 & 1.96 & 1.48 & 2.59 & $<0.001$ \\
\hline Don't know $n=4$ & 6.28 & 0.69 & 56.95 & 4.95 & 0.53 & 46.10 & 0.16 \\
\hline
\end{tabular}

*Facility-related factors: told about pregnancy complication, number of ANC visits, use of contraception, vaccination status, and visiting a health facility in the last 12 months. OR, odds ratio; Lower, lower confidence interval; Upper, upper confidence interval; aOR, adjusted odds ratio; Sig, significance/P-value. 
safer in the hospital. I wonder if one delivers at home if there will be a trained health worker to assist, very risky for complications like bleeding too much.

The best place is the hospital because you deliver in good health and in case of any problems the child is attended to properly. If you are HIV positive you can transmit the infection to the baby at the hospital they try and stop that. In a hospital they can help you if the baby is stuck or if you bleed.

PCN, the opinions and beliefs about the need for a health service also interacted with knowledge about the benefits of FBD. If a woman has a specific health condition, a previous complication, or were worried about their pregnancy, they were more likely to desire FBD.-

It depends on how you feel whether you feel pain or are normal. If you feel pain it is best to go to the hospital. If you are well and strong then that is different. It is different because the pregnancy is normal meaning you will have a normal labour so lots of women deliver at home and that is normal ..... It depends on how you are, I was weak so needed to go to the hospital.

Friends and family thought I would deliver at home but I wanted to deliver in the hospital. I wanted to deliver in the hospital because I have previous $C$ section scars.

My husband is happy for me to deliver at home, he thinks the hospital is costly and far, but when I wanted to go for the 5th he said that was okay because I was scared, and because I hadn't asked before he knew there was a real problem. He trusts me to care of the children.

The reverse was also seen with women acknowledging the benefits of FBD in complications, but explaining that if their pregnancy was normal they did not need FBD.

I always have a choice where to deliver but the reason I delivers at home is because I deliverer quickly and I can't get there in time. I have had no complications and have always been strong and well enough to deliver at home. My husband tells me to go to the hospital but I don't need to.

Sometimes the money is not enough and the midwives at ANC say my pregnancy is okay. I have not much trouble delivering so it is okay and my husband has no trouble with me delivering at home. For me the problem is the money and the distance from home. My husband does not like the cost and now I have delivered so many babies okay I cannot change now because I have no need to pay the costs when I have done it at home and my husband knows I can do it at home.

The money and costs are too much so it is better not to go with no problem.

At home it is not as much expense because if you don't have money you can still deliver at home. They fear being cost a lot of money, you might have to sell your land to pay for the hospital fees but if you can keep your land you can grow food on it and look after your children.

\section{Socio-cultural factors}

Socio-cultural factors were assessed through the qualitative interviews only. Positive views about FBD and the benefits of facility care from a society can be incentives for women to receive FBD.

Yes it is good to go the hospital everyone knows that.

Obviously in the hospital, because everyone knows it is best and you should go if you can.

Whereas societal opinions that discourage FBD are that pregnancy, labour and home deliveries are normal and safe.

Many people think it is normal to have the baby at home.

Most of them deliver their babies at home as they think they can make it and they see everyone else do it at home so they think it is safe especially if they are strong and have had other babies.

They expected me to deliver from the village, because they say it is better and that is where they deliver from and most of the old people also used to deliver from home.

The community's views on place of delivery seemed to change depending on the condition and health of the women and pregnancy. This links to PCN, with women expressing that the hospital is for complications and problems.

They deliver at home but a few go to hospital. If it is the first pregnancy and they produce well at home then they don't change, they stay producing at home. But if there is a complication that is when they rush to hospital and go back for the next one.
Some deliver from home and others from the hospital it depends on how strong they are and how there pregnancy is. I have been strong and delivered healthy babies so my family and husband are happy. I am very well and strong for delivering, I have no problems. It is when you have problems that you run to the hospital. It is all about life and death you do it and you don't know, if you die you die and if you live you live.

Most of the people deliver from home, but others in hospital it depends on how there pregnancy is - if they have problems they go to the hospital. For no problems it is okay but a risk for when the complications come.

He expected me to come to the hospital because I was weak and expecting three babies is hard.

A deterrent to facility based care was the negative opinions on caesarean section, whilst being able to push was seen as a good thing.

They discourage me from going to the hospital as they say they section you for no good reason.

Maybe they cut you and don't let you push, I have a friend that that has happened too, and they make you pay more for having the surgery.

With my second baby everything was normal so I could push which was good, having a caesarean was different. It will be very expensive and I have a scar and a weak stomach.

I also see TBA during pregnancy because they give you other help and drinks to make you strong. They want you to be able to deliver without the surgery. No the TBAs want to help you push, but they are happy for you to push in the hospital.

In many of the quotes women use emotive words such as "weak" and "strong" when describing how and where women should deliver. Those women who pushed or delivered at home where described as strong, whilst delivery at home or caesarean sections where seen as weak.

Some go to the hospital and some deliver at home; I think this is because those who go to the hospital think that when they fail they will be helped. I think that if you cannot deliver at home you are weaker.

I have been sectioned each time so I 
think it is bad. If you don't push people think you are not confident enough to try and that you are weak.

Sometimes you cannot get to the hospital, like when it is night and you cannot get transport, but you can still be strong and push at home.

There were examples of women choosing to have a FBD despite their community's opinions and some women described a cultural shift in delivery location.

They tell you home is best, but I know they are wrong so I just smile at them and then there is no problem.

They did not influence the place because now there is a mixture of women delivering at home and at hospital. Not everyone delivers at home so it is okay.

No, we do not worry about those things, Uganda is becoming more modern and people are moving on from the old ways.

Today in Uganda most people go to hospital only a small number of people remain behind. It is improving day by day.

In Uganda individuals can seek healthcare in a number of ways including the use of herbs, traditional medicines, traditional practitioners, health centres or hospitals. A theme identified through the interviews was the use of traditional care verses "western care". The majority of the women interviewed used traditional medicines, and there appeared to be a hierarchy as to when and what healthcare was used. Not many women interviewed used TBA and those that did use TBA's did not necessarily deliver with them.

I also use traditional medicines for things like deworming - when they are small problems and we have the medicine, I use traditional medicines. This is sensible as it saves you money and stops you leaving home. It is when it is a big problem and you don't have a solution that you should travel to the hospital.

Sometimes they use traditional herbs some conditions are simple and can be treated by herbs - like a cough should be treated with herbs. If the problem is bad or doesn't go away you should go to the clinic and if it is very bad you should go to the hospital.

I use both medical and traditional medicines; I use traditional herbs for things like when the child has diarrhoea. I use them at different times, first I use traditional medicines and then if the child does not recover then I use that of the medical clinic or hospital.

For the second baby I felt the pains and the leaking so I started to travel but then could feel to push so I returned home and delivered there, then the TBA came and helped me and gave me medicines to keep me strong... I also saw them during pregnancy... They told me to come to the hospital for $A N C$ and to deliver from the hospital because they also know it is safer. They just help you make sure you are healthy before and after you labour.

\section{Facility-related factors}

Every facility is unique, placed within a cultural context, with specific attributes that act either as barriers or incentives for women. Facility-related factors include costs and distance, quality of care, patientstaff relationships, ANC influence and any problems with care received. In the DHS, increased use of facility services in general was significantly associated with having had a FBD of the last-born child in both univariate and multivariable analysis: previous vaccinations, modern contraception methods, and use of ANC services were positively associated with FBD (Table 3). ANC was also seen to encourage FBD through the interviews.

I had been to the health centre for ANC so I knew they were good and would care for me.

Yes in the old times patients said that if you went to Kisiizi they could be rude to you, but now there is outreach and so you see the health workers and they are better, not rude how they used to be.

My last baby was in Kisizi but it is not my local hospital, it is the furthest. I came here because they had cared for me well (ANC) and given me a date to return for caring before the delivery.

I believe what the health professionals tell you, because they tell you the truth that they know. They tell you it is best to go to the hospital because of the equipment at the hospital and how they can help you.

ANC could also reduce the incentive to seek FBD through normal findings reducing woman's PCN and reassuring women or their families that it was not necessary to seek FBC.

Also the nurses said the baby was normal at ANC and in the right place to push so I had less to worry about.
When I had the pregnancy checks and told him everything was normal he would say it was better not to go to the hospital because everything is okay.

Although care was mostly quoted as an incentive for FBD, there were several ideas discussed in the interviews that were specific attributes of facility care that acted as barriers to FBD. These included caesarean sections, ANC and relationships between patients and healthcare staff. However, many women expressed improvements in this area.

Because the child has malnutrition I face stigma and they, the nurses and doctors will abuse me and think I am a bad mother because I cannot care for my son. I appreciate the advice and care that they give me and they care about the child and they get better and I am satisfied with the care but I don't like the stigma. There are lots of reasons I cannot care for my son, and now they are telling me to pay for different milk, because they say my child cannot have normal milk and things. I think they do not understand and have always lived in cities without many problems. In admission I am always stigmatised because I cannot afford to pay for the children and so they give me stigma and tell me how to be a mother.

Some if they are tired, can be angry and hard to the patients which is why sometimes the patients feel stigma and are afraid to come to the hospital because they think that they will not be treated well by staff.

Before some of the health workers were bad. Now they are better. They were rude and treated you stupid. For my first delivery the healthcare staff where rude.

They are kinder than the past. I think they understand now that the child's sickness is not always the mothers fault.

\section{Discussion}

Most maternal deaths occur during the intra-partum and immediate post-partum period, often from unpredictable complications; therefore FBD reduces risks to both mother and baby significantly. ${ }^{4,17,18}$ Despite improvements, with over $60 \%$ of women in the Ugandan 2011 DHS reporting FBD, the results presented here highlight that some sections of Ugandan society still predominantly deliver unaided in the community. ${ }^{19,20}$ Reasons behind the underuse of facilities are complex and interacting, 
including logistics, demographics, PCN and cultural beliefs. ${ }^{9-13}$

Interviews found that the barriers of cost and distance were important in the decision, and for some women they were so obstructive as to remove all choice. However, the barriers of cost and distance to FBD are not the whole picture, with other factors such as SES, education level and place of residence influencing their relative importance. ${ }^{9-11}$ These interacting factors offer explanations for the finding from the multivariable analysis of DHS data. Women from an urban area, who are generally closer to facilities, are three-fold more likely to deliver in a facility than women from rural areas and women from the upper four wealth quintiles were 1.5 to 3.7 -fold more likely to deliver in a facility than those in the lowest quintile for whom costs are most obstructive.

The restrictive impact of cost and distance on receiving FBD shows the importance of removing them as barriers. ${ }^{13,14,21}$ This can be achieved through increasing free facilities or ambulance services as well as designing interventions that reduce their impact such as community health insurance or waiting houses for expecting mothers, as being initiated in Kisiizi hospital. ${ }^{4,18,22}$ However, with the reality of overstretched budgets, poor infrastructure and socio-cultural barriers, solely focusing on removing these barriers is not always feasible or effective. ${ }^{4,22,23}$ Therefore this study would suggest other reasons women don't receive FBD are also addressed.

The recently published intervention study Saving Mothers, Giving Life supports this approach, with comprehensive interventions to improve access to and quality of care, which were built upon existing health strategies, resulting in a $30 \%$ reduction in population based MM in Uganda over one year. ${ }^{24}$ This intervention design used the three delays model, which splits factors that stop effective FBD into delays in seeking appropriate services, delays in reaching those services and then delays in receiving timely and quality care at the facilities. ${ }^{24}$ This highlights the importance of not only providing facilities, but also encouraging women to use then, and insuring they are adequate quality, concurring with the findings of this study. ${ }^{24}$

A major way to promote women seeking appropriate services identified in this study was education about the benefits of FBD and the risks of labour. ${ }^{25,26}$ Women's PCN and knowledge about the benefits of FBD were shown to influence women's willingness to overcome barriers, with women in the interviews choosing to overcome barriers if they believed it necessary, whereas low PCN justified home delivery. ${ }^{16,26}$ This was also seen in the DHS data with women educated to secondary level three-times more likely to receive FBD than those without formal education, and women told about the complications of pregnancy 1.5- times more likely to receive FBD than those not told.

ANC can be a tool used to deliver this education, alongside having several other effects on delivery location and MM. ANC monitors pregnancies, identifies high risk situations and allows for community level interactions between patients and staff, ${ }^{22}$ which if positive, can allow for fear to be reduced and trust to develop between facilities and women. ${ }^{11,15}$ However ANC can act as a deterrent to $\mathrm{FBD}$, through negative experiences and normal finding were shown to reassure women and reduce their PCNs for FBD. ${ }^{22}$

Developing trust between communities and facilities will be essential in increasing FBD, but this will only be achieved if facilities provide good quality care. Large numbers of maternal and neonatal deaths occur in facilities, and interestingly some studies have shown that neonatal maternity is not reduced through FBD. ${ }^{27-29}$ This is thought to be explained by facilities lacking skilled personnel and necessary equipment. Again, 1 the success of the Saving Mothers, Giving life intervention initiative, which aimed to provide evidence-based interventions in facilities, with facilities upgraded with medical equipment and staffing, showed that MMR fell by $35 \%$, confirming that good quality facilities is essential to effectively reduce neonatal and maternal mortality. ${ }^{24}$

Along with promoting knowledge about the benefits of FBD, education can promote gender equality, increase earning potential, and contribute to changing societal norms around delivery locations. ${ }^{9,30}$ A common belief is that if women had greater autonomy they would choose FBD. ${ }^{15,30}$ However, in the 2011 DHS data there were no significant difference in delivery location when the decision was taken by women or their partners. In Uganda males traditionally take the major decisions. ${ }^{13}$ Some interviewed women explained if their husband did not give them permission or money then FBD was impossible. For other women, permission from family members gave them the resources to receive FBD. Family acting as both a barrier and enabling factor to FBD may reflect disagreements within the literature..$^{9,13,15}$ Therefore this study would suggest that alongside women, men and the wider community should be educated about the benefits of FBD.

Societies have opinions on whether healthcare providers are good or bad, when it is appropriate to seek healthcare and where it should be sought from. This is seen specifically through the case of childbirth, with how a community views childbirth determining what healthcare is viewed as appropriate. As with PCN the societal belief that pregnancy and labour are normal and therefore hospital care is unnecessary can discourage FBD. ${ }^{13,23}$ It is worth considering whether this view of FBD as unnecessary is linked to the beliefs that western healthcare should only be sought in severe illness or as a last resort. Through the interviews traditional medicine appeared to be used first, with western medicine used when the problem was severe or wasn't healing after being treated with the traditional medicines.

This theory was identified for general healthcare usage in this study, and for obstetric care in Uganda in a study by Kyomuhendo. ${ }^{13}$ These are hypothesised as explanations for the delays in women going to facilities and why facility benefits, as seen by the community, predominantly focus on complications. More research would be beneficial in this area not solely to promote FBD, but to generally encourage the appropriate usage of healthcare.

Another societal barrier to FBD hypothesised through these interviews was that weaker women sought FBD whilst stronger women could deliver at home unaided. This could also be linked to the negative opinions about caesarean sections, as women who had caesarean sections seemed to experience some stigma, whilst woman who pushed to deliver vaginally were described as strong. If women believe seeking FBD makes them weaker, this could be a major deterrent to FBD. Again, Kyomuhendo identified similar findings, identifying cultural beliefs that strong women deliver unaided. ${ }^{13}$ In these interviews many women identified a cultural shift in delivery location favouring FBD, resulting in positive reinforcement, with increasing numbers of women receiving FBD, increasing its social acceptability and dispelling some negative cultural beliefs.

\section{Strengths}

There is considerable literature about the demographics behind women's delivery locations, whilst far less is known about the socio-cultural factors. The qualitative interviews allowed these to be explored along with identifying potential causal relationships to the statistical associations.

\section{Limitations}

The 2011 Uganda DHS is cross sectional, with data collected up to five years after delivery; data may thus be subject to recall and reporting bias. The DHS data depends 
on key informant responses at household level and may not be the best way to investigate individual socio-cultural factors, which is the rationale behind conducting additional interviews.

Selection and recruitment of women through Kisiizi hospital could introduce biases: social desirability bias, as it is not neutral when discussing choices between hospital and home; selection bias as women were more likely to have knowledge and experience of the hospital. This could also be due to Kisiizi's good reputation as a nongovernment hospital and its insurance system meaning it is not an accurate representation of a Ugandan hospital. These were addressed by explained confidentiality and outreach recruitment of women.

\section{Conclusions}

The influence of factors on women's choice of place of delivery is unique, with each woman having a specific balance of incentives and barriers determining their final decision. ${ }^{9-11,23}$ Those women least likely to receive FBD are also most likely to be affected by socio-cultural pressures discouraging FBD ${ }^{19,20}$ Therefore, this study would suggest that there is no single intervention enough to successfully increase FBD rates among all population groups, and therefore interventions should take a broad approach, aiming to tip this balance in favour of FBD. These should target women least likely to delivery in a facility, women from a low SES and rural area, to ensure they are not left further behind.

\section{References}

1. WHO. Trends in maternal mortality: 1990 to 2015. Estimates by WHO, UNICEF, UNFPA, World Bank Group and the United Nations Population Division. 2015. Available frm: http://apps.who.int/iris/bitstream/10665 /194254/1/9789241565141_eng.pdf?ua $=1$

2. Ronsmans C, Graham WJ, group LMSSs. Maternal mortality: who, when, where, and why. Lancet 2006;368:1189-200.

3. Gribble J, Haffey J. Reproductive health in Sub-Saharan Africa. Population Reference Bureau. 2008. Available from: http://www.prb.org/pdf08/reproductivehealth_subsaharanafrica.pdf

4. Kongnyuy EJ, Hofman JJ, van den
Broek N. Ensuring effective essential obstetric care in resource poor settings. BJOG 2009;116:41-7.

5. Campbell OM, Graham WJ, group LMSSs. Strategies for reducing maternal mortality: getting on with what works. Lancet 2006;368:1284-99.

6. Darmstadt GL, Marchant T, Claeson M, et al. A strategy for reducing maternal and newborn deaths by 2015 and beyond. BMC Pregnancy Childbirth 2013;13:216.

7. Zureick-Brown S, Newby H, Chou D, et al. Understanding global trends in maternal mortality. Int Perspect Sex Reprod Health 2013;39:32-41.

8. Hogan MC, Foreman KJ, Naghavi M, et al. Maternal mortality for 181 countries, 1980-2008: a systematic analysis of progress towards Millennium Development Goal 5. Lancet 2010;375: 1609-23.

9. Gabrysch S, Campbell OM. Still too far to walk: literature review of the determinants of delivery service use. BMC Pregnancy Childbirth 2009;9:34.

10. Thaddeus S, Maine D. Too far to walk: maternal mortality in context. Newsl Womens Glob Netw Reprod Rights 1991:22-4.

11. Moyer CA, Mustafa A. Drivers and deterrents of facility delivery in subSaharan Africa: a systematic review. Reprod Health 2013;10:40.

12. Parkhurst JO, Rahman SA, Ssengooba F. Overcoming access barriers for facility-based delivery in low-income settings: insights from Bangladesh and Uganda. J Health Popul Nutr 2006;24:438-45.

13. Kyomuhendo GB. Low use of rural maternity services in Uganda: impact of women's status, traditional beliefs and limited resources. Reprod Health Matters 2003;11:16-26.

14. McPake B, Witter S, Ensor T, et al. Removing financial barriers to access reproductive, maternal and newborn health services: the challenges and policy implications for human resources for health. Hum Res Health 2013;11:46.

15. Tey NP, Lai SL. Correlates of and barriers to the utilization of health services for delivery in South Asia and SubSaharan Africa. Sci World J 2013;2013:423403.

16. Kabakyenga JK, Östergren PO, Turyakira E, Pettersson KO. Influence of birth preparedness, decision-making on location of birth and assistance by skilled birth attendants among women in south-western Uganda. PLoS One 2012; 7:e35747.

17. Say L, Chou D, Gemmill A, et al.
Global causes of maternal death: a WHO systematic analysis. Lancet Glob Health 2014;2:e323-33.

18. Mbizvo MT, Say L. Global progress and potentially effective policy responses to reduce maternal mortality. Int J Gynaecol Obstet 2012;119:S9-12.

19. Giroux SC, Eloundou-Enyegue PM, Lichter DT. Reproductive inequality in sub-Saharan Africa: differentials versus concentration. Stud Fam Plann 2008;39:187-98.

20. Victora CG, Barros AJ, Axelson H, et al. How changes in coverage affect equity in maternal and child health interventions in 35 Countdown to 2015 countries: an analysis of national surveys. Lancet 2012;380:1149-56.

21. Parkhurst JO, Ssengooba F. Assessing access barriers to maternal health care: measuring bypassing to identify health centre needs in rural Uganda. Health Policy Plan 2009;24:377-84.

22. Ediau M, Wanyenze RK, Machingaidze $\mathrm{S}$, et al. Trends in antenatal care attendance and health facility delivery following community and health facility systems strengthening interventions in Northern Uganda. BMC Pregnancy Childbirth 2013;13:189.

23. Stephenson R, Baschieri A, Clements S, et al. Contextual influences on the use of health facilities for childbirth in Africa. Am J Public Health 2006;96:8493.

24. Serbanescu F, Goldberg HI, Danel I, et al. Rapid reduction of maternal mortality in Uganda and Zambia through the saving mothers, giving life initiative: results of year 1 evaluation. BMC Pregnancy Childbirth 2017; 17:42.

25. Doctor HV, Findley SE, Cometto G, Afenyadu GY. Awareness of critical danger signs of pregnancy and delivery, preparations for delivery, and utilization of skilled birth attendants in Nigeria. J Health Care Poor Underserved 2013;24:152-70.

26. Dako-Gyeke P, Aikins M, Aryeetey R, et al. The influence of socio-cultural interpretations of pregnancy threats on health-seeking behavior among pregnant women in urban Accra, Ghana. BMC Pregnancy Childbirth 2013;13:211.

27. Kananura RM, Tetui M, Mutebi A, et al. The neonatal mortality and its determinants in rural communities of Eastern Uganda. Reprod Health 2016;13:13.

28. Kananura RM, Wamala R, EkirapaKiracho E, et al. A structural equation analysis on the relationship between maternal health services utilization and newborn health outcomes: a cross-sec- 
tional study in Eastern Uganda. BMC Pregnancy Childbirth 2017;17:98.

29. Kassar SB, Melo AM, Coutinho SB, et al. Determinants of neonatal death with emphasis on health care during pregnancy, childbirth and reproductive history. J Pediatr (Rio J) 2013;89:269-77.

30. J Espey, N. Dolata. An equal start. Why
Gender equality matters for child survival and maternal health. London: Save the Children UK; 2011. 